\title{
A "função desenvolvente" das artes dramáticas na sala de literatura estrangeira
}

Bárbara Ann Newman

\begin{abstract}
Professora no Curso de Letras na Universidade Católica Dom Bosco, Mato Grosso do Sul, (as então Faculdades Unidas Católicas de Mato Grosso - FUCMT). Desde 1988 ministra a disciplina Literatura Inglesa. Mestranda no Programa de Mestrado em Educação da UCDB.
\end{abstract}

"Eu ouço, e eu esqueço. Eu escuto e eu lembro. Eu faço e eu compreendo." (Provérbio chinês)

O presente artigo baseia-se em 6 anos de experiência no ensino de Literatura Inglesa (Britânica) no curso de Letras na Universidade Católica Dom Bosco (as então Faculdades Unidas Católicas de Mato Grosso - FUCMT). Outrossim, faz parte avaliativa da disciplina "Metodologia de Trabalho Científico" do curso de Mestrado em Formação de Professores da mesma universidade. Esta disciplina é ministrada pelo Dr. Prof. Vicente Fideles Ávila.

\section{"A função desenvolvente das artes dramáticas"}

O termo "função desenvolvente" no uso das artes dramáticas vem, desde a década dos anos 50, ocupando espaço como ferramenta no ensino das disciplinas escolares. Dentro daquela função, as artes dramáticas fazem com que o educando participe, de forma física e atuante, no processo ensino-aprendizagem através de dramatizaçōes de acordo com a matéria em questão. É importante observar que estas dramatizaçōes não visam à presença de uma platéia, uma vez que o objetivo principal é o benefício e o desenvolvimento do participante naquele processo.

\section{A questão lingüística na sala de literatura estrangeira}

Durante o primeiro ano do Curso de Letras, todos os acadêmicos, seguindo a grade curricular, freqüentam aulas de língua inglesa. Para a maioria, é a primeira experiência séria de aprendizagem da língua. Ao fim do segundo semestre, o acadêmico deve decidir se continua ou não o curso com língua inglesa. Para a maioria que faz esta opção, o domínio da língua está na fase elementar. No terceiro semestre, começa a disciplina de literatura ingle- 
sa que continua até o oitavo semestre, totalizando seis semestres. Obviamente, o pulo lingüístico, exigido pelo próprio texto literário em questão, apresenta um desafio substancial para o professor e o acadêmico. Como fazer viável a apreciação literária é o problema que surge. Tal desafio merece uma atenção específica e se torna oportuno, já que se faz presente em três anos da vida do acadêmico e engloba uma parcela considerável da sua carga horária.

\section{Dramatização como resposta}

Uma resposta que tentamos e confirmamos ter dado resultado positivo é a do uso da dramatização durante o curso.

Uma consideração hermenêutica mostra que este termo, conforme a sua aplicação, tem várias interpretaçōes. Em primeiro lugar, é preciso distinguir entre "teatro", que é produzido para uma platéia, e as dramatizaçōes com fins educativos. Com esta segunda finalidade, encontramos várias terminologias. Dougill (1987) fala de "dramatização informal". Ele usa este termo para abranger tudo o que é dramatizado, menos o teatro com platéia. Heathcote (1984) os diferencia, dizendo que em teatro tudo é feito para agradar a platéia e, na sala de aula, o aproveitamento dos participantes. Entretanto, esta autora acrescenta que as ferramentas para os dois são as mesmas, isto é, os elementos da técnica teatral. Reverbel (1987) fala em drama contextualista, para a sala de aula sem platéia, e drama essencialista, que se destina a "teatro" com platéia. Seu trabalho segue a linha essencialista. Courtney (1968), na sua obra clássica a respeito do uso das artes dramáticas em educação, oferece referenciais mais detalhados da termologia destas atividades:

teatro - representar perante uma platéia jogo - atividade a que nos dedicamos simplesmente porque desfrutamos

jogo dramático - jogo que contém personificação e/ou identificação

jogo de regra - formalização do jogo em modelos com regras.

Courtney (1968) em sua abordagem sobre a Educação Dramática refere-se aos seus principais componentes metodológicos, distinguindo-os em:

1. Método Dramático: a utilização do jogo dramático na aprendizagem de várias disciplinas como história, geografia, etc.

2. Teatro como tal: jogo dramático com fim em si voltado para desenvolvimento pessoal... e como disciplina independente no currículo; e aqui encontramos os vários elementos da matéria:

improvisaçāo (teatro criativo)

movimento criativo

discurso criativo

e com estudantes mais velhos, teatro (ou teatro escolar).

\section{Dramatização na educação}

Segundo Courtney (1968), as origens desta forma de encarar a educação, na filosofia, remetem-se a Platāo, Aristóteles e Rousseau, fundamentando-se tanto na antropologia e psicoterapia infantil. Originam-se, em parte, das modernas teorias behavioristas da imitação, na psicolingüística e na psicologia do desenvolvimento de Piaget. Neste contexto, é o centro da edu- 
cação criativa moderna donde brotam todas as artes. As disciplinas intelectuais que apóiam este trabalho se encontram nas seguintes áreas:

a) a da Filosofia Educacional que trata, entre outros itens, da história do pensamento, evolução, pensamento moderno da educação, e outros que buscam esclarecer as diversas etapas no processo educacional;

b) a da Psicologia Profunda, abordando os princípios da psicanálise, psicoterapia e psicodrama, no intuito de acrescentar dados teóricos para a pesquisa; fortalece, e ao mesmo tempo embasa, uso da "função desenvolvente" da dramatização;

c) a da Antropologia Social, preocupada com as origens do teatro, estudos de grupo e psicologia social, contém nestes itens subsídios suficientes para reforçar o uso da "função desenvolvente" da dramatização;

d) a da Cognição, que estuda aprendizagem social, formação de conceito, psicolingüística, linguagem e pensamento, e constitui forte aliada também na aplicação da "função desenvolvente" da dramatização;

e) a das disciplinas teatrais, tais como: Teatro Criativo, Movimento Criativo, Linguagem Criativa e Teatro Escolar; juntas, possibilitam e viabilizam a prática da "função desenvolvente" da dramatização.

Para este estudo, limitamo-nos ao apoio intelectual encontrado na "Filosofia Educacional" acima mencionada. Aqui Courtney apresenta, em forma linear, a presença das artes dramáticas desde o século $V$ a.C. até o século XX. Para apoiar a nossa solução ao problema, destacamos, desta e outras obras, seis funçōes da arte dramática. Da sexta surge o contexto para enqua- drar a solução encontrada. No tratamento destas funçōes, nenhuma se encontra isolada mas uma se sobressai em relação às outras em determinadas épocas. Como diz Revervel (1993: 74):

Na síntese, (...) percebe-se a linha de interpretação desenhando-se, sinuosamente, de uma época a outra, umas dando continuidade a uma linha anterior, outras cortando-a bruscamente; (...).

\section{Funções das artes dramáticas}

Não é o propósito deste artigo exaurir e justificar estas funçōes. Mesmo assim, incluímos aqui algumas noçōes a respeito delas por questão de inteireza.

a) A função filosófica

A função filosófica manifestou-se principalmente em torno dos grandes nomes da filosofia. Aristóteles, em sua Poética, enfatiza a arte dramática com uma imitação de idéias abstratas. A sua teoria de catarse sugere que as emoçōes despertadas pela tragédia purgavam a alma como um remédio. Platão, por outro lado, na sua República, não dá lugar ao teatro visto que este exige o imitar ou fuga da realidade.

No pensamento romano, Cícero descreveu o teatro como "uma cópia da vida". Horácio, entre outros conceitos, achou que açōes violentas não deveriam ser apresentadas e Sêneca condenou o palco porque este desviava o povo da séria ocupação de aprender e escrever seus próprios dramas, não para o teatro, mas para o estudo.

b) A função educativa

A função educativa vem da antiguidade do século $V$ a.C., da educação atenien- 
se, quando se memorizavam passagens de Homero com todos os recursos teatrais. $\mathrm{Na}$ época Tudor, na Inglaterra, Wolsey (1568) encorajou o teatro para a aquisição da linguagem. Goethe, sumarizado por Coggin (1967), distinguia o teatro profissional do teatro educacional. Ele apoiava o segundo. Schiller considerava o teatro escolar benéfico já que exigia habilidades de memória, gestos e disciplina interna.

\section{c) A função litúrgica}

A função litúrgica ou moralista teve grande destaque nos ensinamentos medievais da Igreja, através das chamadas Peças de Mistérios e Moralidades.

\section{d) A função lúdica}

A função lúdica foi reconhecida por Aristóteles que deu destaque ao jogo na educação. Ele percebeu que certas atividades têm um fim em si mesmas enquanto outras, como certos jogos, são recursos direcionados para um fim. Esta função fez-se presente com maior força no fim do século XVIII e no início do século XIX, com a obra "Emile" de Rosseau (1762), na qual propōe que a primeira educação da criança se faça quase inteiramente através de jogos. Foi por esta porta que Froebel, Pestalozzi, Montessori, Dewey, e Caldwell Cook entraram com as suas teorias de educação.

e) A função entretenimento

A função entretenimento é uma constante no mundo das artes dramáticas. Nunca falta quem se fascine pela produção dramática. Uma época de auge desta função foi o período de Elizabeth I, na Inglaterra, com as peças não somente de Shakespeare como também de crianças da Chapel Royal, dos estudantes das Universidades de Oxford e Cambridje e de acadêmicos de Direitos em Londres. Nos dias de hoje, com os luxuosos "shows" da Broadway, Nova Yorque, das TVs, e dos sistemas de vídeo, o entretenimento é a função que mais preocupa os envolvidos.

\section{f) A "função desenvolvente"}

A "função desenvolvente" aparece no século XX, nos anos 50 e 60 na Inglaterra, e começa a separar o uso de drama em educação do teatro propriamente dito. Slade e Way, a partir de 1958, apresentam o aspecto "desenvolvente" da arte dramática em educação. Eles vêem o uso do drama como caminho à maturidade no sentido de auto-expressão, criatividade e a conscientização do "eu". Way (1967) desenvolve a tese do drama como a realização do potencial do indivíduo. Heathcote (1984) defende a idéia de que o drama fomenta o desenvolvimento social, intelectual e lingüístico da pessoa. Ela isolou cinco características do drama educacional como especialmente significativas:

- o drama exige a cooperação dos participantes;

- o drama aproveita a experiência anterior;

- o drama cria situações nas quais há a necessidade de comunicação precisa;

- o drama proporciona uma experiência além do intelectual;

- o drama desafia os estudantes a descobrirem novas verdades ou discernimentos no confronto de situaçōes anteriormente desconhecidas. 


\section{A "função desenvolvente" na sala de literatura estrangeira}

Baseado nestes trabalhos, o drama entrou como ferramenta para o ensino de qualquer disciplina. Assim dentro da "função desenvolvente" da arte dramática, encontramos o apoio teórico para o uso da mesma na disciplina de literatura em língua estrangeira e, especificamente, em literatura inglesa.

\section{0 papel da imaginação criativo- dramática no processo}

Lembramos que o problema proposto para ser superado é o do conhecimento elementar da língua no início e ao longo dos estudos de literatura inglesa. Esta dificuldade, entretanto, conta com um forte aliado na característica essencial de cada pessoa, e de sua imaginação criativa. E esta característica que o capacita a dominar seu meio de modo tal que supere as limitações de seu cérebro de seu corpo e do universo material.

Courtney diz que a imaginação criativa é essencialmente dramática em sua natureza. Atuamos todos os dias com nossos amigos, nossa família e com estranhos. A imagem mais comum para caracterizar esse processo é a da "máscara e a face": o nosso verdadeiro "eu" está escondido pelas muitas "máscaras" que assumimos durante o decorrer de cada dia.

Atuar é o método pelo qual convivemos com o nosso meio encontrando adequação através do jogo. A criança, durante o dia, está jogando com o mundo externo para poder compreendê-lo. À medida que ficamos mais velhos, este jogo se torna cada vez mais interno até que, quando adultos, passa a ser automático: jogamos dramaticamente, em nossa imaginação, a tal ponto interiorizarmos que, inclusive, podemos até nem mesmo perceber o que fazemos. Para Courtney, o processo dramático é um dos mais vitais para os seres humanos. Sem ele, seríamos meramente uma massa de reflexos motores com poucas qualidades humanas.

Cada época busca a própria forma de educação e a necessidade do nosso tempo é a desenvolver um processo educativo que cultive o "homem total", processo esse que se concentre nas habilidades criativas do ser humano. A imaginação dramática deve ser ajudada e assistida por todos os métodos modernos de educação. Dentro da história do pensamento humano, a natureza educacional da dramatização tem sido compreendida por vários pensadores em diferentes épocas, mas dentro dos seus próprios termos. A educação esteve relacionada com a estrutura global do pensamento na qual o indivíduo esteve inserido. São estas consideraçōes que nos levam a buscar a razão pela qual a dramatização trouxe uma solução para o problema focado na área de língua estrangeira.

\section{Campo de experiência das atividades}

As atividades foram realizadas com acadêmicos de Letras do terceiro ao oitavo semestres ou seis turmas do Curso de Letras. Normalmente o tempo permite até seis 
apresentaçōes por turma/semestre em forma de grupo. Cada obra apresentada é estudada em sala de aula usando metodologia variada que inclui exposição, pergunta e resposta, filmes, mesa redonda, panoramas e atividades para facilitar a identificação cultural com estas técnicas mais tradicionais, procuramos destacar épocas, características literárias, a construção das obras, a evolução de estilo e assim por diante.

\section{Os tipos de dramatização}

Citaremos oito tipos de dramatização que têm sido a base destas experiências.

a) O "Tableau" Narrado de Personagens. Esta técnica consiste em selecionar personagens de determinada obra, após um estudo da época em forma de mesa redonda na sala de aula.

Cada acadêmico assume uma das personagens e se encarrega de pesquisar a sua função na obra, o seu tipo da época em questão, seu relacionamento com outros personagens e de preparar, por escrito, um parágrafo com as respectivas informaçōes. Além disso, o acadêmico faz o possível para se vestir conforme as informaçōes colhidas durante a pesquisa. Como atividade de grupo, o "Tableau" é formado na sala de aula, quando possível com cenário, música adequada e narração dos parágrafos preparados pelos acadêmicos. A apresentação do "Tableau" é o ponto máximo deste processo.

b) O "Tableau" Falado de Personagens. Este consiste no mesmo processo acima descrito, mas, ao invés de um narrador, cada personagem apresenta a sua pesquisa vestida a caráter.

Aqui, o acadêmico muitas vezes tem mais iniciativa e inclui mais dramatização, já que neste ponto a contribuição é livre.

c) "Tableau" de uma cena ou de cenas de um livro. Aqui, os acadêmicos lêem o livro e fazem a escolha de uma cena ou a montagem de uma cena composta de vários momentos do livro. Isto é seguido do trabalho de pesquisa, de distribuição de tarefas, etc., para a apresentação da cena.

d) Diálogo de um livro ou uma peça. Esta técnica consiste em escolher um diálogo chave da obra. Tal diálogo deve demonstrar um aspecto da construção literária, quanto ao desenvolvimento da obra, nas suas partes de introdução, encaminhamento de açōes, conflito, clímax ou desfecho. Este diálogo pode ser feito com as personagens a caráter, tentando aproximarse da realidade da obra. Uma outra maneira seria a de fazer em forma de silhueta, trabalhando a imaginação criativa. Estas duas técnicas podem ser usadas juntas quando há interferências a eventos anteriores, de maneira que a silhueta represente o tempo psicológico. Desta forma, o acadêmico visualiza a sua compreensão da construção da obra e a manipulação do tempo pelo autor.

e) O Conto dramatizado. Em relação ao Conto, por se tratar de obra menor, a apresentação pode cobrir a sua totalidade. A manipulação do tempo já é indicada com a mudança da luz, a azul representando tempo psicológico. O passar do tempo com movimentos em "câmara lenta" é um recurso de bom efeito. Representações desse tipo já foram encenadas para os seguintes con- 
tos: "The Happy Prince", de Oscar Wilde; "The Lagoon", de Joseph Conrad; "The Luncheon", de Somerset Maugham; "The Case of the Middle-Aged Wife", de Agatha Christie.

f) A Poesia Dramatizada. Esta técnica consiste em selecionar as poesias de uma época para ilustrar uma determinada tendência. Já foi utilizada para poesias que relatam experiências da Primeira Guerra Mundial. Trata-se de uma forte apresentação, vez que o tema une uma poesia a outra, penetrando os sentimentos de patriotismo, sofrimento, separação, glória e morte. E o momento de sentir o conceito de temas universais que provocam a reação poética de todas as épocas. Efeitos para as poesias de guerra incluíram uma máquina de fumaça, luz vermelha para os tiros, slides de fotografias tiradas na época da primeira guerra mundial e trincheiras feitas de sacos de pó de serragem. Uma outra poesia, "Silver" de Walter de la Maré, com fundo musical de "Clair de la Lune", de Debussy, personifica a lua no seu trajeto noturno prateando o campo. No seu passeio, a lua prateia as unhas de um camundongo, o peixe no riacho, as patas do cachorro, etc. A apresentação foi no escuro com luz negra realçando magnífico efeito. "The Great Lover", de Rupert Brooke, foi dramatizado através de uma galeria de arte mostrando objetos reais de tudo o que o poeta confessa ter amado. Foi uma experiência sensorial rica e o grupo ofereceu chá e pão para encerrar a apresentação. "The Listeners", de Walter de la Maré, à luz de vela, com um cavalo de camurça e fantasmas silenciosos fixou para sempre a misteriosa poesia.

g) O Cinema Mudo. Neste caso, seleciona-se geralmente um dos filmes de
Carlitos (Sir Charles Chaplin) e algumas cenas são apresentadas para ilustrar a construção do filme com os mesmos componentes de uma obra literária. A mímica aqui é central na atuação e se usam também cartazes com palavras para fazer as ligaçōes necessárias. A música escolhida reflete a época e o costume de acompanhar a ação no piano.

h) Solilóquios. Esta técnica oferece oportunidade para o acadêmico se realizar numa apresentação Shakespeareana. O solilóquio pode ser gravado e dramatizado; memorizado e dramatizado; ou lido por um e dramatizado por outro acadêmico. Tudo exige profundo entendimento do texto, da função do solilóquio e das mudanças de realidade que ele normalmente apresenta.

i) O Vídeo-Debate Ensaiado. Esta técnica surgiu após o estudo de uma série de letras das músicas dos Beatles. Os acadêmicos trouxeram um vídeo com Beatles em Show, o qual serviu de fundo para um "debate ensaiado" pelos acadêmicos sobre a época dos anos 60, o papel da música dos Beatles e o conteúdo da letra.

\section{Benefícios do processo}

Os resultados visíveis, em termos de mensuraçōes, não foram ainda colhidos, mas, mesmo assim, podemos apresentar alguns dos benefícios vistos e comentados pelos acadêmicos:

a) a visualização da obra obriga a compreensão total do texto e da construção literária;

b) neste mesmo processo a manipulação do tempo pelo autor, em real e psico- 
lógico, é plenamente entendido com a dramatização;

c) para apresentar uma personagem de modo convincente, o acadêmico aprofunda-se não somente no texto (em busca dos traços psicológicos) mas também na época com detalhes de roupa, mobília e artefatos;

d) enseja o viver de uma época;

e) a geografia surge como elemento importante quanto à vegetação, roupas, moradia, etc., (por exemplo, no "The Lagoon" que se passa na Malaya);

f) fisicamente, o acadêmico descobre as expressōes faciais e corporais, através da mímica, levando-o à grande apreciação do gênio "Carlitos";

g) conforme a obra, fortes ensinamentos de vida são captados como, por exemplo, a psicologia do casamento em "The Case of the Middle-Age Wife", de Agatha Christie;

h) o humor está sempre presente ou nas obras ou nos ensaios que exigem bastante do acadêmico;

i) a fantasia assume uma nova dimensão na leveza de Oscar Wilde, com "The Happy Prince", bem como as fortes emoçōes de um amor incrível.

Talvez o mais emocionante de todos os benefícios seja o de liberar o perfume da obra literária do frasco das palavras, como diz Fausto Cunha (1967):

O poeta concebe a última forma de sua poesia como uma representação verbal. Mas esta representação é apenas documento - um frasco que guarda e protege o perfume mas não é o perfume.

\section{A seleção de obras para dramatização}

A seleção de obras para a realização desta "função desenvolvente" da arte dramática é de suma importância, devendo-se levar em consideração a praticidade, o interesse, a representatividade do corpo literário e o objetivo a ser alcançado com a atividade. Cabe ao professor conduzir o processo de forma que a experiência seja de crescente realização individual e grupal no decorrer dos três anos.

\section{Comentários finais}

A presença de um problema no desenrolar acadêmico é sempre uma oportunidade para a descoberta de alternativas cada vez mais criativas. O problema lingüístico que provocou esta busca jamais se resolve definitivamente já que a aprendizagem de uma língua, embora ajudada pela atividade dramática, tem suas próprias técnicas e exigências de tempo. Entretanto, a "função desenvolvente" proporciona o envolvimento intenso com o texto e permite que tudo dentro dele fique mais vivo, mais iluminado, mais compreensível e quase inesquecível. Este tem sido o nosso objetivo e a arte dramática nos tem proporcionado a sua consecução. 


\section{Bibliografia}

BENTON, Michael; BENTON, Peter (eds.). Touchstones. London: Hodder e Stoughton, 1971.

BRENDON, P.; SHAW, W. (eds.). Readings they've liked. London: Macmillan, 1967.

BOLTON, Gavin. Drama as education - an asrgument for placing drama at the centre of the curriculum. London: Longman, 1984.

CASE, D.; WILSON, Ken. Off-stage. London: Heinemann, 1978.

COLLIE, Joanne; SLATER, Stephen. Literatura in the language classroom. Avon: Cambridge University Press, 1987.

COSTA, Lígia Militiz da. A poética de Aristóteles. São Paulo: Ática, 1992.

COURTNEY, Richard. Jogo, teatro e pensamento. São Paulo: Perspectiva, 1968.

DUNLOP, Frank. Human nature, learning and ideology. The British Journal of Educational Studies, 23/3, October 1977.

DOURGILL, John. Drama activities for language learning. London: Macmillan Publishers, 1987.

GIBSON, James (ed.). Let the poet choose. London: Harrap, 1975.

HEATHCOTE, Dorothy. Training needs for the future, HODGSON, J.; Banham, M. (eds.). Education I - the annual survey. [S.I.]: Pitman, 1972. In: JOHNSON, E.; O'NEILL, C. (eds.). Dorothy Heathcote: collected writings on education and drama. [S.I.]: Hutchinson, 1984.

LONERGAN, Jack. Video in language teaching. Cambridge: Cambridge University Press, 1984.

NIXON, J. (ed.). Drama and the whole curriculum. [S.I.]: Hutchinson, 1982.

REVERBEL, Olga. Teatro. atividades na escola. Porto Alegre: Kuarup, 1989.

. O texto no palco. Porto Alegre: Kuarup, 1993.

. Oficina de teatro. Porto Alegre: Kuarup, 1993.

SLADE, P. An introduction to child drama. [S.I.]: Longman, 1967.

SMITH, Stephenb M. The theatre arts and the teaching of second languages. London: Addison - Wesley, 1984.

WAGNER, Betty Jane. Dorothy Heathcore: drama as a learning medium. London: Hutchinson, 1979.

WAY, Brian. Development thouugh drama. London: Longman, 1987.

WESSELS, Charlyn. Drama. Oxford: Oxford University Press, 1987. 
